\title{
Sleep spindles as an early biomarker of REM sleep disorder in a rat model of Parkinson's disease cholinopathy
}

\author{
Ciric J ${ }^{1}$, Lazic K ${ }^{1}$, Petrovic $J^{1}$, Kalauzi $A^{2}$ and Saponjic $J^{{ }^{*}}$ \\ ${ }^{1}$ Department of Neurobiology, Institute for Biological Research - Sinisa Stankovic, University of Belgrade, Serbia \\ ${ }^{2}$ Department of Life Sciences, Institute for Multidisciplinary Research, University of Belgrade, Serbia
}

\begin{abstract}
Rhythmic oscillations of neuronal populations, generated by different mechanisms, are present at several levels of the central nervous system and serve many important physiological or reflect pathological functions. Understanding the role of brain oscillations as possible biomarkers of brain function and plasticity is still a challenge, and despite extensive research, their role is still not well established.

We recently demonstrated that the hallmarks of earlier aging onset during impaired thalamo-cortical cholinergic innervation (in a rat model of Parkinson's disease cholinopathy) were consistently expressed, from 3 and one half to 5 and one half months of age, through increased electroencephalographic (EEG) sigma activity amplitude during rapid eye movement (REM) sleep, as a unique aging induced REM sleep phenomenon. In addition, there was altered motor cortical drive during non-rapid-eye-movement (NREM) and REM sleep.

In order to explain this new aging-induced REM sleep phenomenon, we analyzed possible differences between control REM sleep spindle activity and REM sleep spindle activity at the onset of REM sleep "enriched“ with sigma activity (at 4 and one half months of age), following bilateral pedunculopontine tegmental nucleus (PPT) cholinergic neuronal loss in the rat. We analzyed differences in spindle density, duration, and frequency.
\end{abstract}

We demonstrated in young adult Wistar rats with the severely impaired PPT cholinergic innervation the alterations in sleep spindle dynamics and pattern during REM sleep in the motor cortex as the earliest biomarkers for the onset of their altered aging processes.

\section{Introduction}

Rhythmic oscillations of neuronal populations, generated by different mechanisms, are present at several levels of the central nervous system and serve many important physiological functions such as hippocampal theta activity, occipital alpha waves, and sleep spindles [1]. Rhythmic oscillations may also underlie the basis of behavioral states, as well as neurological diseases such as epileptic convulsions or rhythmic movement disorders [2]. There are an increasing number of reports on the association between sleep spindles and alterations in diseases such as schizophrenia [3], Parkinson's disease [4], REM sleep behavioral disorder [4,5], Alzheimer's disease [6,7], autism [8], mental retardation [9], memory consolidation, intelligence [10], sleep preservation [11], and with recovery processes following brain stroke [12].

Understanding the role of brain oscillations as possible biomarkers of brain function and plasticity is still a challenge, and despite extensive research, their role is still not well established. Sleep spindles, as the hallmark of NREM sleep, are EEG oscillations in the sigma frequency range, that last, as the waxing and waning oscillations from $0.5-3.0 \mathrm{~s}$ [13]. Sleep spindles are generated by complex interactions between GABAergic neurons of thalamic reticular nucleus (RT) and thalamocortical (TC) nuclei, and are synchronized across multiple thalamic nuclei via neocortical feedback [14]. Since sleep spindles result from interactions between thalamic reticular, talamo-cortical, hippocampal, and cortical neurons, their characteristics may reflect the integrity of these circuits or serve as biomarkers of their dysregulation [15].

Our recent study showed that the hallmark of earlier aging onset in a rat model of Parkinson's disease cholinopathy were consistently expressed, from 3 and one half to 5 and one half months of age, through the increased EEG sigma activity amplitude during REM sleep, as a unique aging-induced REM sleep phenomenon. In addition, there was altered motor cortical drive during NREM and REM sleep [16].

In order to explain this new aging-induced REM sleep phenomenon, in this study we analyzed possible differences between control REM sleep spindle activity and REM sleep spindle activity at the onset of REM "enriched" with sigma activity (at 4 and one half months of age), following bilateral PPT cholinergic neuronal loss in the rat. We analzyed differences in spindle density, duration, and frequency.

\section{Materials and methods}

We performed the experiments in 36 adult male Wistar rats, chronically instrumented for sleep recording at the age of 2 and one half months, and randomly assigned to two experimental groups: physiological controls $(n=18)$, and bilateral PPT lesioned rats $(n=18)$.

Correspondence to: Jasna Saponjic, University of Belgrade, Department of Neurobiology, Institute for Biological Research - Sinisa Stankovic, Despot Stefan Blvd., 142,11060 Belgrade, Serbia, Tel: + 38111 2078426; Fax: + 38111 2761433; E-mail:jasnasap@ibiss.bg.ac.rs

Key words: sleep spindles, oscillations, REM sleep disorder, pedunculopontine tegmental nucleus, Parkinson's disease, cholinopathy

Received: June 03, 2017; Accepted: July 19, 2017; Published: July 21, 2017 
Prior to surgery and throughout the experimental protocol, the animals were maintained on a $12 \mathrm{~h}$ light-dark cycle, and were housed at $25^{\circ} \mathrm{C}$ with free access to food and water. All experimental procedures were in compliance with EEC Directive 2010/63/EU on the protection of animals used for experimental and other scientific purposes, and were approved by Ethical Committee for the Use of Laboratory Animals of the Institute for Biological Research "Sinisa Stankovic", University of Belgrade (Approval No 2-21/10).

\section{Surgical procedure}

The surgical procedures employed for the EEG and EMG electrode implantation for chronic sleep recording and bilateral PPT lesion have been described previously [16-24], and are outlined below.

We implanted under ketamine/diazepam anesthesia (Zoletil 50, VIRBAC, France, $50 \mathrm{mg} / \mathrm{kg}$; i.p.), in 2 and one half months old rats, 2 epidural stainless steel screw electrodes for EEG cortical activity from the motor cortex (A/P: $+1.0 \mathrm{~mm}$ from bregma; $\mathrm{R} / \mathrm{L}$ : $2.0 \mathrm{~mm}$ from sagittal suture; $\mathrm{D} / \mathrm{V}: 1.0 \mathrm{~mm}$ from the scull surface) [25]. Bilateral electromyogram (EMG) stainless steel teflon coated wire electrodes (Medwire, NY, USA) were implanted into the dorsal nuchal musculature to assess skeletal muscle activity, and a stainless steel screw electrode in the nasal bone as a ground. All the electrode leads were soldered to a miniature connector plug (39F1401, Newark Electronics, Schaumburg, IL, USA), and the assembly was fixed to the screw electrodes and skull using acrylic dental cement (Biocryl-RN, Galenika a.d. Beograd, Serbia).

During the surgical procedure for implantation of the EEG and EMG electrodes, we performed bilateral PPT lesions. The excitotoxic lesions were induced using stereotaxically guided microinfusion of 0.1 $\mathrm{M}$ ibotenic acid (IBO)/0.1 M phosphate buffered saline bilaterally into the PPT (A/P: $-7.8 \mathrm{~mm}$ from bregma; R/L: $1.9 \mathrm{~mm}$ from the sagittal suture; D/V: $7.0 \mathrm{~mm}$ from the brain surface) [25], using a Digital Lab Standard Stereotaxic Instrument with Hamilton syringe $(1 \mu \mathrm{l})$.

The IBO (Sigma; $\mathrm{pH}=7.4$ ) concentration was chosen on the basis of previous studies [16,18,20,23,26]. The microinfusions were introduced at a volume of $100 \mathrm{nl}$, using a single, $60 \mathrm{~s}$ pulse. Following microinfusion, the Hamilton syringe was left within the local brain tissue for $5 \mathrm{~min}$ before removal from the brain, allowing the IBO solution to diffuse. After removal from one side of the brain, the needle of Hamilton syringe was always washed using saline, and then it was inserted again into the PPT on the other side of the brain, for the next IBO microinfusion.

\section{Sleep recording and data analysis}

Following two weeks of postoperative recovery, we recorded spontaneous sleep during $6 \mathrm{~h}$ of normal inactive circadian phase for rats (from 9 a.m. to 3 p.m.). The EEG and EMG activities were displayed on a computer monitor, and stored on disk for further offline analysis. Briefly, after conventional amplification and filtering (0.3 - $100 \mathrm{~Hz}$ band pass; A-M System Inc. Model 3600, Calborg, WA, USA), the analog data were digitized (at a sampling frequency of 256/s) using DataWave Sci Works Experimenter Version 8.0 (DataWave Technologies, Longmont, CO, USA). For the analysis of sleep and sleep spindles, we used sleep recordings of the 3 months and 4 and one half months old rats at the onset of aging-induced REM sleep disorder (REM "enriched" with sigma activity within the motor cortex along with severely altered motor cortical drive) in the PPT lesioned rats, as previously described [16].
The analysis of the recorded signals was conducted using software developed in MATLAB 6.5 [16,18-23], and upgraded to MATLAB R2011a. We applied Fourier analysis to signals acquired throughout 6 h (2160 $10 \mathrm{~s}$ Fourier epochs), and each $10 \mathrm{~s}$ epoch was differentiated, on the basis of EEG and EMG, as Wake, NREM, or REM sleep state (Figure 1). The differentiation of all Wake/NREM/REM sleep epochs was improved by using the logarithmic values of the quantities on both EEG and EMG axes, and was finally achieved using the two cluster $\mathrm{K}$ means algorithm [16,18-23].

In order to additionally demonstrate that the differentiation of the NREM/REM sleep epochs were done in the same way in the control and the PPT lesioned rats, we used scattergrams of the linear correlations of sigma and theta relative amplitudes, as the EEG hallmarks for light NREM and REM sleep (Figure 2).

To analyze REM sleep EEG microstructure, we calculated the group probability density distributions of all conventional EEG frequency bands relative amplitudes over $6 \mathrm{~h}$, using the Probability Density Estimate (PDE) routine supplied by MATLAB R2011a [16,18-20,22-24].

Additionally, we analyzed the REM sleep corticomuscular coherence (CMC) for each experimental group at each age, and for all the conventional EEG frequency bands, using the EEG from the motor cortex and the EMG of the dorsal nuchal muscles [16,21]. The CMC values were calculated using the "cohere" routine of the MATLAB R2011a Signal Processing Tool box [16,21].

In order to identify sleep spindles (SS) at the onset of REM sleep "enriched" with sigma activity within the motor cortex, alongside severely altered motor cortical drive in PPT lesioned rats at 4 and one half months of age, we combined automatic SS detection with visual validation of all detected SS for their final visual extraction (Figure 3). Namely, the first step for automatic SS detection during REM sleep was to concatenate all the extracted $10 \mathrm{~s}$ epochs of REM sleep from motor cortex for each rat, each experimental group, and then to filter the EEG signals using the $11-17 \mathrm{~Hz}$ band pass filter. Then, we applied the Continuous Wavelet Transform with the mother wavelet "cmorl-2" MATLAB R2011a function, providing a complex Morlet wavelet with determined central frequency $f_{0}=2$ [27]. In addition, all SS had a minimal duration of $0.5 \mathrm{~s}$.

Since we automatically detected many false positive SS, we visually corrected the automatically detected SS, and visually extracted them for each REM sleep episode of each rat, and each experimental group ( $n=7$ for controls; $n=5$ for PPT lesioned rats), and then concatenated all SS for each group of rats. Finally, for the analysis of SS dynamics at the onset of REM sleep "enriched" with sigma activity within the motor cortex, we used the assembly of 842 SS extracted from 7 control rats, and the assembly of 1216 SS extracted from 5 PPT lesioned rats.

All statistical analyses were done using the Kruskal Wallis ANOVA with post hoc Mann Whitney $U$ test. For the statistical analysis of $\mathrm{PDE} / 6 \mathrm{~h}$ and CMC/6 h during REM sleep episode, we calculated the means for every $30 \mathrm{~min}$.

\section{Tissue processing and histochemistry for the PPT lesion verification}

We identified the PPT lesion using NADPH diaphorase histo chemistry [28]. The rats were deeply anesthetized and perfused transcardially, starting with a vascular rinse until the liver had been cleared ( $200 \mathrm{ml}$ of $0.9 \%$ saline; perfusion speed of $40 \mathrm{ml} / \mathrm{min}$ ); followed 


\section{3 months}
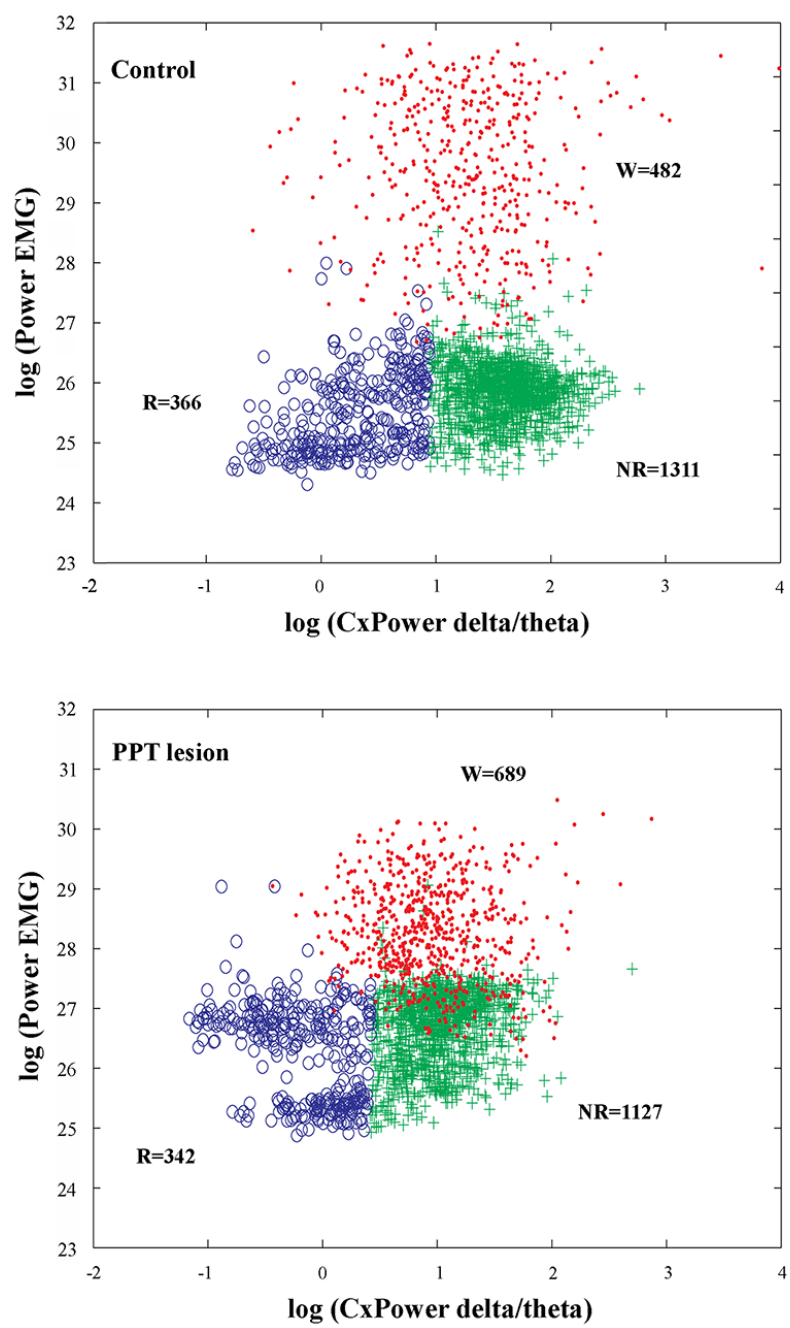

4.5 months
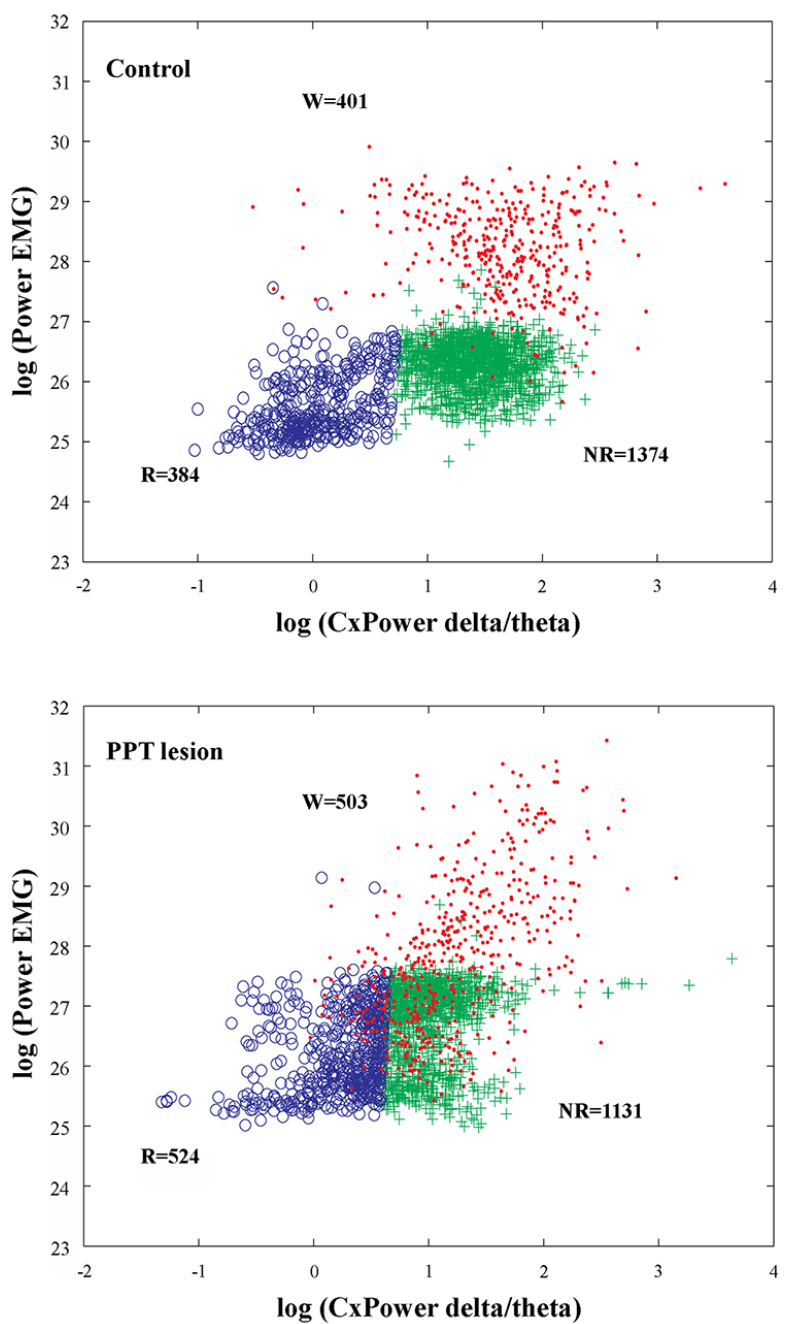

Figure 1. Examples of scattergrams of the Wake/NREM/REM sleep $10 \mathrm{~s}$ epochs during $6 \mathrm{~h}$ of sleep recordings and across aging (at 3 months and 4 and one half months of age) within the motor cortex of control (upper panels) and PPT lesioned rats (bottom panels). The Wake $10 \mathrm{~s}$ epochs were only transferred to these final scattergrams from the preceding Wake/Sleep differentiation, using the product of EEG sigma and theta frequency power on the y-axis and the total EMG power on the $\mathrm{x}$-axis. W - Wake cluster dots (Wake $10 \mathrm{~s}$ epochs); NR - NREM cluster crosses (NREM $10 \mathrm{~s}$ epochs); R - REM cluster circles (REM $10 \mathrm{~s}$ epochs).

by a $4 \%$ paraformaldehyde solution in $0.1 \mathrm{M}$ PBS $(200 \mathrm{ml} ; 100 \mathrm{ml}$ at $40 \mathrm{ml} / \mathrm{min}$, and then $30 \mathrm{ml} / \mathrm{min}$ ), and finally with a $10 \%$ sucrose solution in $0.1 \mathrm{M} \mathrm{PBS}(200 \mathrm{ml} ; 30 \mathrm{ml} / \mathrm{min})$. The animals were sacrificed, perfused, and the brains were extracted, cleared of the meninges and blood vessels, and immersed in $4 \%$ paraformaldehyde overnight, and then in $30 \%$ sucrose solution for several days. The brains were cut in a coronal plane into $40 \mu \mathrm{m}$-thick sections using a cryotome, and the free-floating sections were stained, mounted, and coverslipped with DPX (Sigma), and then examined under a Zeiss Axiovert microscope equipped with a camera. Briefly, the free-floating sections were rinsed in $0.1 \mathrm{M} \mathrm{PBS}, \mathrm{pH}=7.4$, and incubated for $1 \mathrm{~h}$ at $37^{\circ} \mathrm{C}$ in the staining solution - a mixture of the substrate solution with $\beta$-nicotinamide adenine dinucleotide phosphate, reduced $\mathrm{Na} 4$ salt ( $\beta$-NADPH, Serva), and dimethyl sulfoxide (DMSO, Sigma). The substrate solution contained dissolved nitro blue tetrazolium chloride (NBT, Serva), and 5bromo-4chloro-3indolyl phosphate (BCIP, Serva) in the substrate buffer at $\mathrm{pH}=9.5(0.1 \mathrm{M}$ Tris, $100 \mathrm{mM} \mathrm{NaCl}, 5 \mathrm{mM} \mathrm{MgCl})$. To reduce the background staining from endogenous alkaline phosphate, the specific inhibitor levamisole (Sigma) was added to the staining solution to produce a final concentration of $2 \mathrm{mM}[16,18,22]$.

All the tissue samples of both experimental groups were grouped into three defined stereotaxic ranges of the PPT rostro-caudal dimension. We quantified the cholinergic cell loss using Image J 1.46 software. NADPH diaphorase-positive cells were counted in three 40 $\mu \mathrm{m}$ coronal sections within the overall PPT rostro-caudal dimension. The number of NADPH-diaphorase positively stained cells was intended to provide an estimate of the lesion damage or the cholinergic neuronal numbers, rather than an attempt to determine the absolute numbers of cholinergic neurons. The cholinergic neuronal loss was expressed for each side of the brain and for each defined stereotaxic range within the PPT rostro-caudal dimension, as the percent difference of NADPH diaphorase-positive cells versus the controls. To be specific, all the percentage differences were expressed with respect to the mean control absolute numbers for each stereotaxic range, which was taken as $100 \%[16,18,22]$. 
- Control

NREM
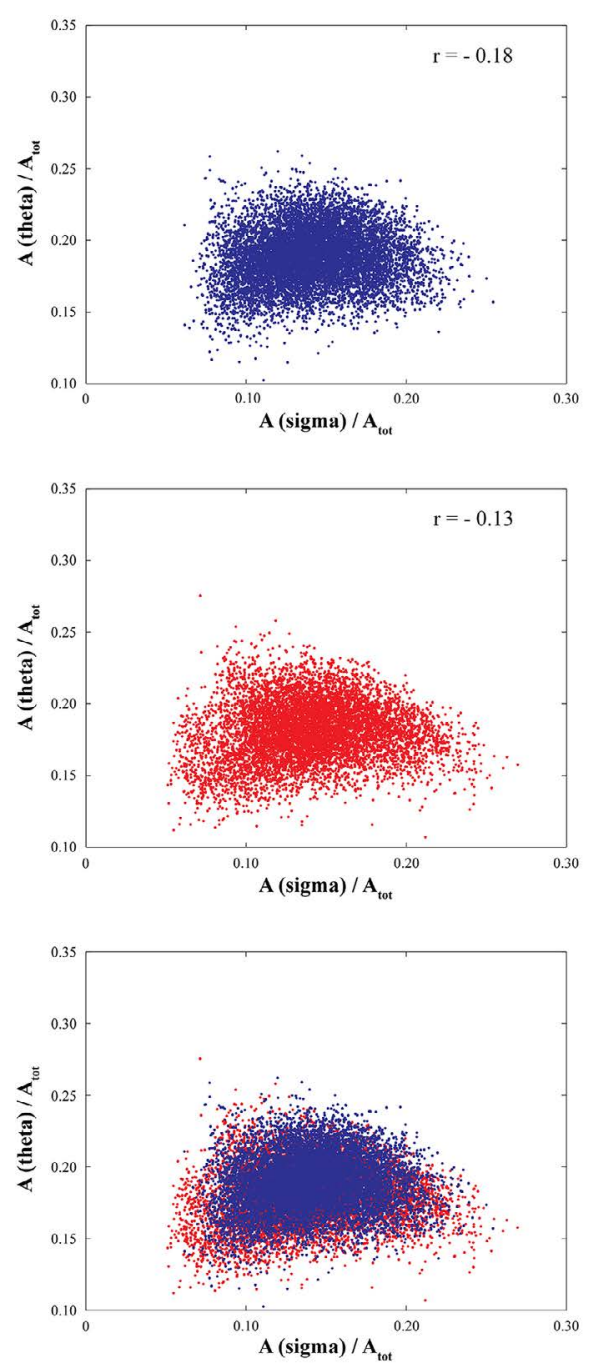

- PPT lesion

REM
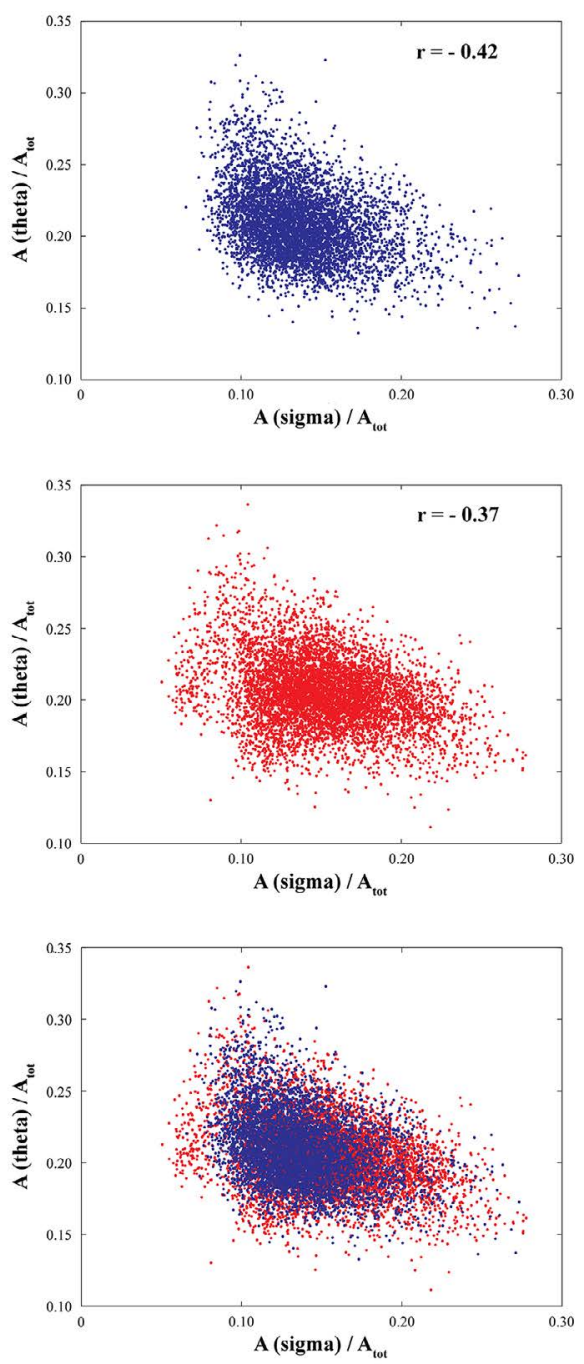

Figure 2. Differentiation of NREM/REM $10 \mathrm{~s}$ epoch based on the linear correlation of relative sigma and theta amplitudes in controls (two upper panels) and PPT lesioned rats (middle panels) at 4 and one half months of age, and their overlapped scatter plots (two bottom panels). In both experimental groups (Controls vs. PPT lesion), there were always a consistent negative theta/sigma correlations during REM vs. NREM sleep.

\section{Results}

Figure 1 depicts the individual examples of Wake/NREM/REM sleep $10 \mathrm{~s}$ epochs differentiation on the basis of EEG and EMG, during $6 \mathrm{~h}$ of sleep recordings (2160 Fourier $10 \mathrm{~s}$ epochs) in control (upper panels) and PPT lesioned rat (bottom panels), at 3 months (left panels) and 4 and one half months (right panels) age. In addition, by using the scattergrams of linear correlations of sigma and theta relative amplitudes, as the EEG hallmarks for light NREM and REM sleep (Figure 2), we were able to demonstrate that differentiation of the NREM/REM sleep $10 \mathrm{~s}$ epochs were done in the same way in the controls and the PPT lesioned rats. These scattergrams were typically the same for the NREM and REM sleep in controls (upper panels) and PPT lesioned rats (middle panels). For the analyses of SS dynamics alteration during REM sleep of the PPT lesioned rats versus controls
(Figure 3 in Materials and Methods), following automatic detection (Figure 3, upper panels), we visually corrected SS detection (Figure 3, bottom panels), and extracted all SS with a minimal duration of $0.5 \mathrm{~s}$.

We demonstrated that there was no progression of cholinergic neuronal loss from 3 months up to 5 and one half months of age, following bilateral PPT lesion (Figure 4A). Namely, this permanent cholinergic neuronal loss within the PPT versus controls was, for each side of the brain $\geq 23.17 \pm 2.74 \%$ throughout the overall rostro-caudal PPT dimension (from 6.90 to $8.60 \mathrm{~mm}$ caudal to bregma), with the highest decrease $\geq 31.78 \pm 2.33 \%$ rostrally (from 6.90 to $7.40 \mathrm{~mm}$ caudal to bregma). A representative example of histological verification of cholinergic neuronal loss throughout the overall rostro-caudal PPT dimension versus control PPT of one side of the brain is shown in Figure 4B. 
A

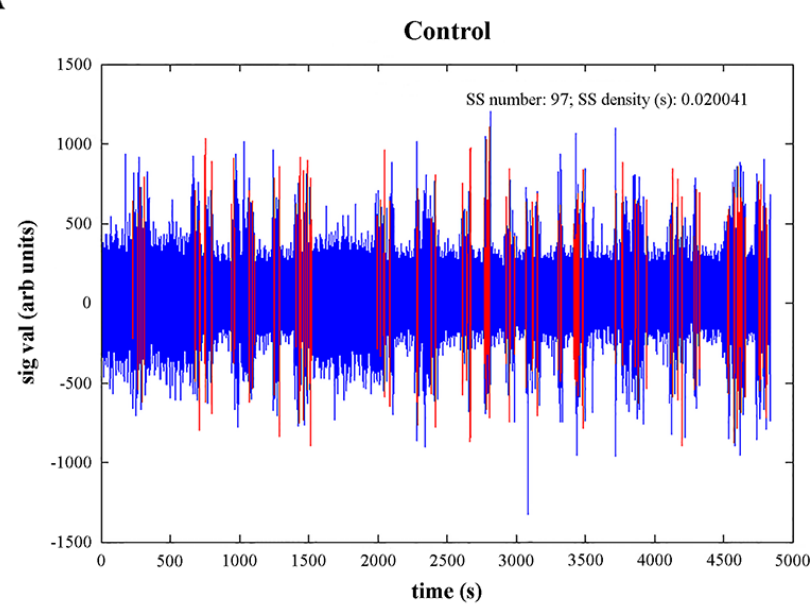

B

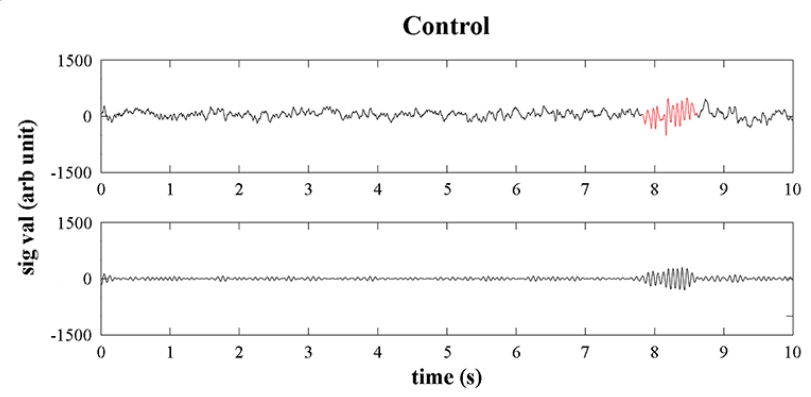

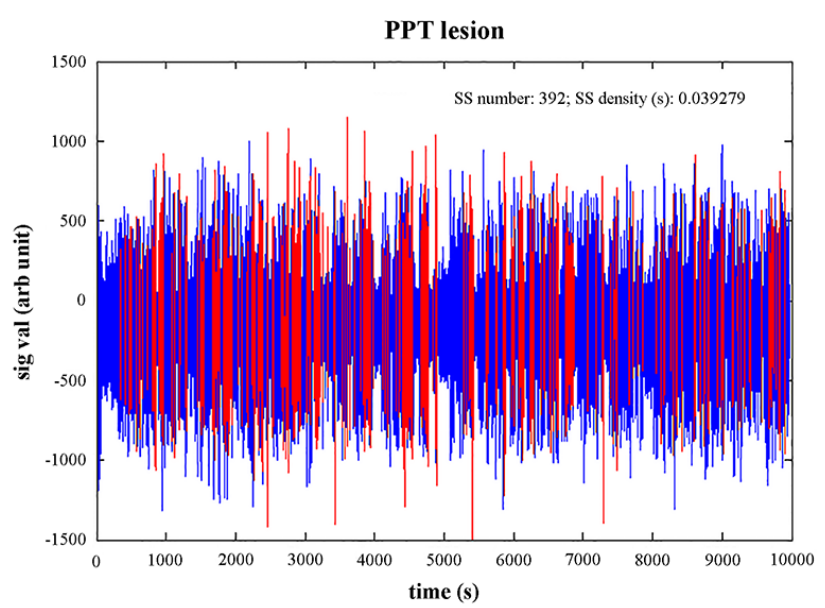

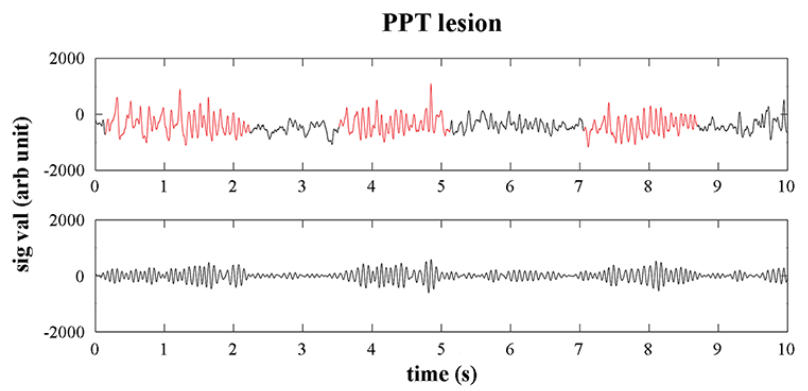

Figure 3. Individual examples of filtered (11-17 Hz band pass filter) and concatenated EEG signals from the motor cortex of control (A, left panel) and PPT lesioned rat (A, right panel) during overall REM sleep per $6 \mathrm{~h}$ of sleep recording, with automatic detection of sleep spindles (A, red), and their examples of analog (B, upper panels) and filtered (B, bottom panels) $10 \mathrm{~s}$ epochs used for visual correction of automatic sleep spindle detection, and their final extraction from the signal.

This partial but selective bilateral PPT lesion augmented EEG sigma amplitude within the motor cortex during REM sleep, with an onset from 4 and one half months of age (Figure $5 \mathrm{~A}, \mathrm{~B} ; \mathrm{z}=-3.299$; $\mathrm{p}=0.001)$. This EEG sigma amplitude augmentation was followed by augmented correlations between theta, sigma, and beta oscillations of EEG from the motor cortex and EMG from the dorsal nuchal muscles (Figure $5 \mathrm{C} ; \mathrm{z} \geq-5.66, \mathrm{p} \leq 10^{-4}$ ). In addition, this augmented EEG sigma activity during REM sleep in PPT lesioned rats was presumably influenced by the significantly increased SS density in the motor cortex (Figure 6A, B; $\mathrm{z}=-2.12 ; \mathrm{p}=0.03$ ). Namely, whereas the control mean SS density during REM sleep in 4 and one half months old rats was 0.016 $\pm 0.003 / 6 \mathrm{~h}$, it was $0.037 \pm 0.009 / 6 \mathrm{~h}$ in PPT lesioned rats (Figure 6B left panel). Along with the higher SS density, the PPT lesion induced SS of more complex pattern (Figure 6A bottom panels; the sleep spindles with mixed intrinsic frequency components), prolonged their mean duration, and reduced their mean intrinsic frequency (Figure 6B, C; $\mathrm{z}$ $\geq-10.45, \mathrm{p} \leq 10^{-3}$ ) during REM sleep. Whereas the control means for SS duration and intrinsic frequency/6 h, during REM sleep were $1.097 \pm$ $0.020 \mathrm{~s}$ and $13.562 \pm 0.029 \mathrm{~Hz}$, their means following PPT lesion were $1.271 \pm 0.019 \mathrm{~s}$ and $13.183 \pm 0.020 \mathrm{~Hz}$, respectively.

\section{Discussion}

We have shown in young adult Wistar rats with reduced PPT cholinergic output the alterations in sleep spindle dynamics and pattern during REM sleep in the motor cortex as the earliest biomarkers for the onset of their altered aging processes.
Apart from altered sleep spindle dynamics (density, duration, intrinsic frequency) during REM sleep (Figure 6), the distinct aging onset in the rat model of Parkinson's disease cholinopathy was manifested as altered EEG microstructure in the motor cortex (augmented sigma amplitude during REM sleep) along with severely altered motor cortical drive (augmented correlations between theta, sigma, and beta oscillations of EEG and EMG activity) during REM sleep (Figure 5).

The term "biomarker" is defined as a "characteristic that is objectively measured and evaluated as an indicator of normal biological processes, pathogenic processes, or pharmacologic responses to a therapeutic intervention" [29]. Also, the term "biomarker" is extensively used in sleep research and sleep medicine [30]. Generally, EEG oscillations are the most widely used biomarkers of sleep processes and vigilance states, and for example, beta activity $(15-35 \mathrm{~Hz})$ is not only a marker of arousal during active wakefulness, but also reflects sleep drive during quiet wakefulness [31]. EEG alpha activity $(8-12 \mathrm{~Hz})$, as the most distinctive EEG pattern of wakefulness, in particular when the eyes are closed, characterizes also the transition from wakefulness to sleep, arousal from sleep, and presents an indicator of neurodegeneration [32].

On the other hand, REM sleep behavior disorder (RBD), as the strongest clinical predictor for the onset of neurodegenerative diseases $[33,34]$, presents a unique opportunity to study the progression of neurodegenerative diseases and to develop neuroprotective therapies for their prevention $[35,36]$. This unique parasomnia, characterized by 
$\mathbf{A}$

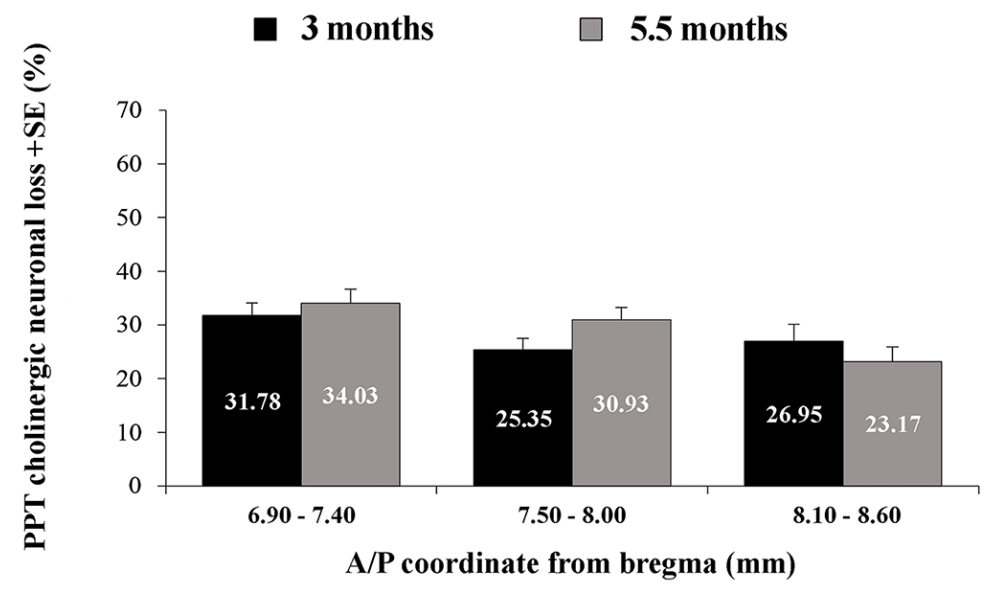

B
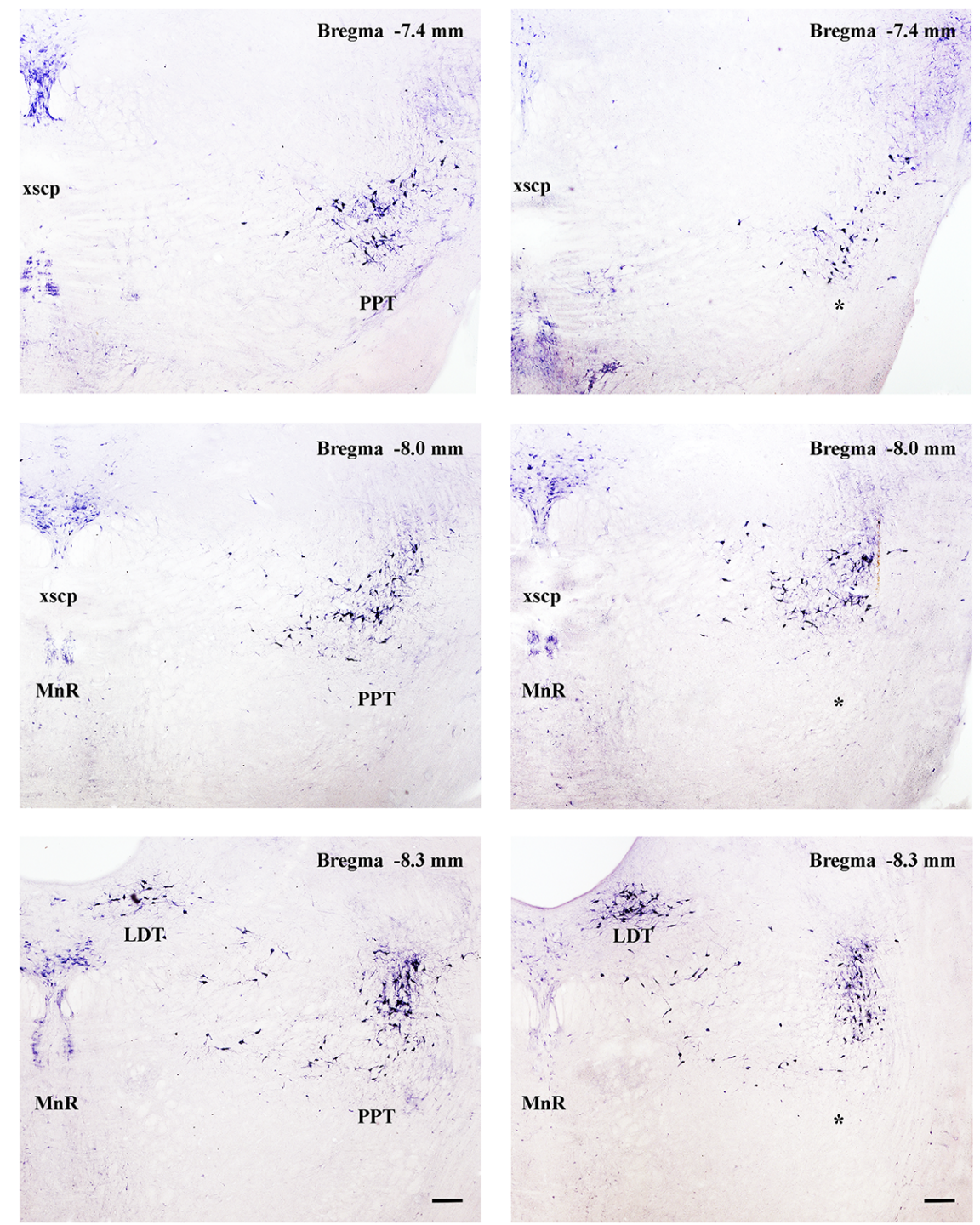

Figure 4. Topography of cholinergic neuronal loss across aging (at 3 and 5 and one half months of age) throughout the rostro-caudal dimension of the PPT (A), expressed as the mean group percent differences + SE of the NADPH diaphorase-positive cells, where the control absolute number of PPT cholinergic neurons, for each stereotaxic level, was taken as $100 \%$ (for 3 months $n=10$ for controls and $n=9$ for the PPT lesioned rats; for 5 and one half months $n=8$ for controls, and $n=9$ for the PPT lesioned rats); and the individual examples of the PPT lesion identification throughout the rostro-caudal PPT dimension vs. control PPT, for each brain side (B). Scale bar for all panels is $200 \mu \mathrm{m}$. 
Control

3 months

A

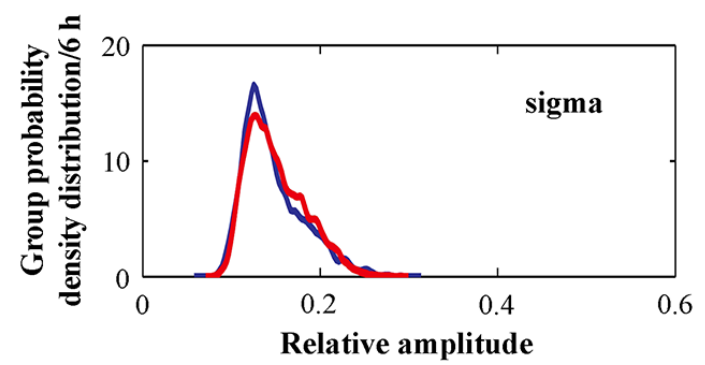

B
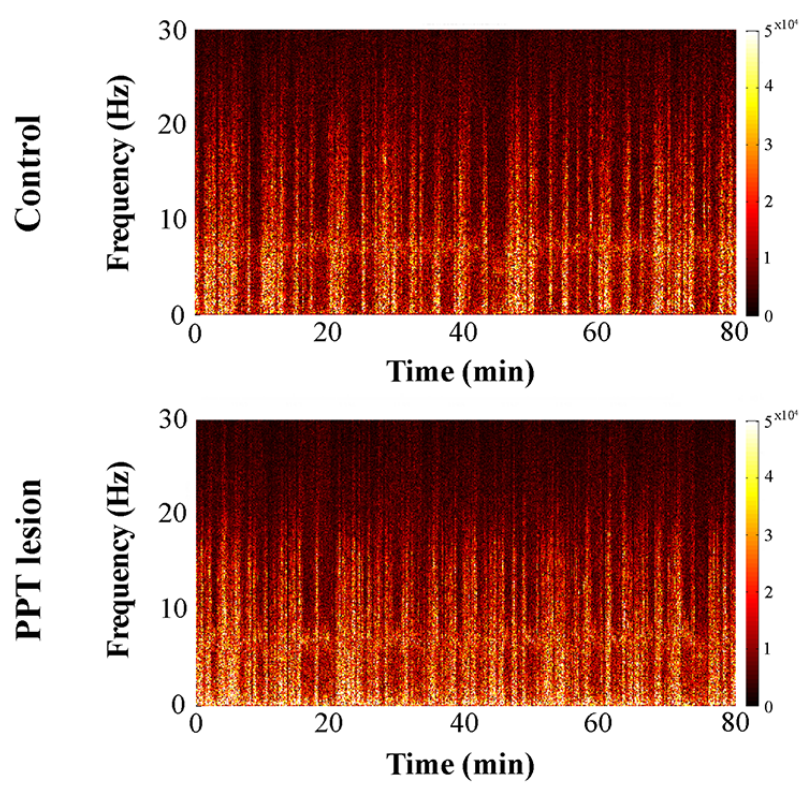

C

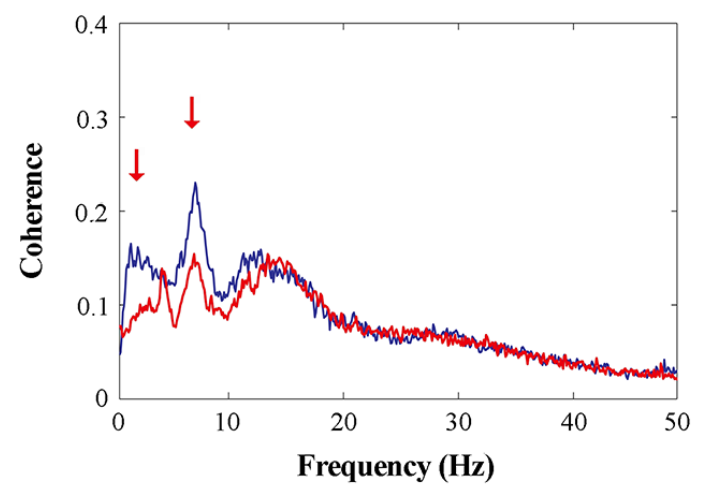

PPT lesion

4.5 months
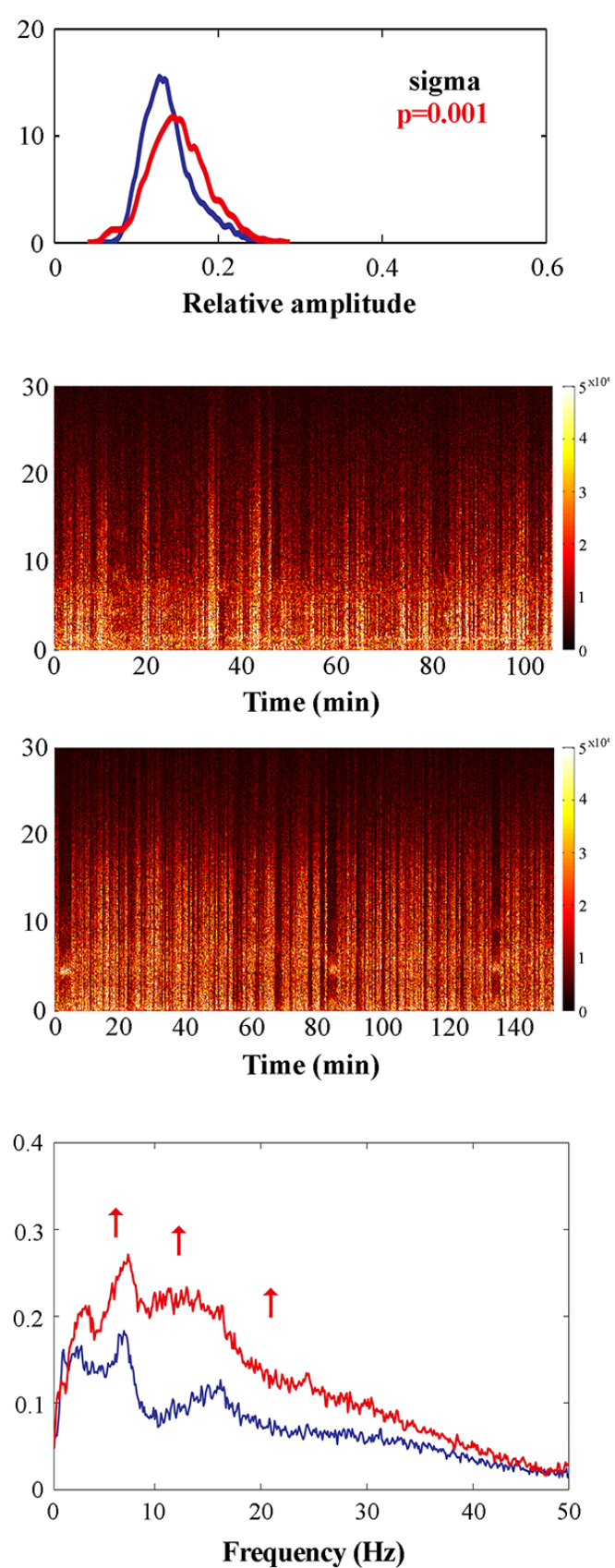

Figure 5. The onset of differing impact of aging on the EEG microstructure during REM sleep in the motor cortex of PPT lesioned rats vs. control rats at 3 months (A, left panel, $n=14$ for the control; $\mathrm{n}=14$ for the PPT lesioned rats), and at 4 and one half months of age (A, right panel, $\mathrm{n}=10$ for the control; $\mathrm{n}=9$ for the PPT lesioned rats). The group probability density distributions of the EEG sigma relative amplitude/ $6 \mathrm{~h}$ during REM sleep showed an age related augmentation of sigma amplitude within the motor cortex in the PPT lesioned rats vs. control rats (the right shifted red distribution) (A). Individual examples of REM spectrograms of the motor cortex in a PPT lesioned rat vs. a control rat at 3 months and at 4 and one half months of age (B). For the REM sleep spectrograms the EEG $10 \mathrm{~s}$ epochs during REM sleep were extracted and concatenated in the same order as they occurred in real-time during the whole $6 \mathrm{~h}$ sleep of each rat, at each condition and age. The group mean coherence spectra between the EEG from motor cortex and the dorsal nuchal muscle EMG during REM sleep in PPT lesioned rats vs. controls $(\mathbf{C})$ at 3 months $(\mathrm{C}$, left panel) and at 4 and one half months (C, right panel) of age. $\mathrm{p}$ values and red arrows correspond to the obtained significant result of Mann-Whitney U two-tailed test $\left(\mathrm{p} \leq 10^{-3}\right)$. 


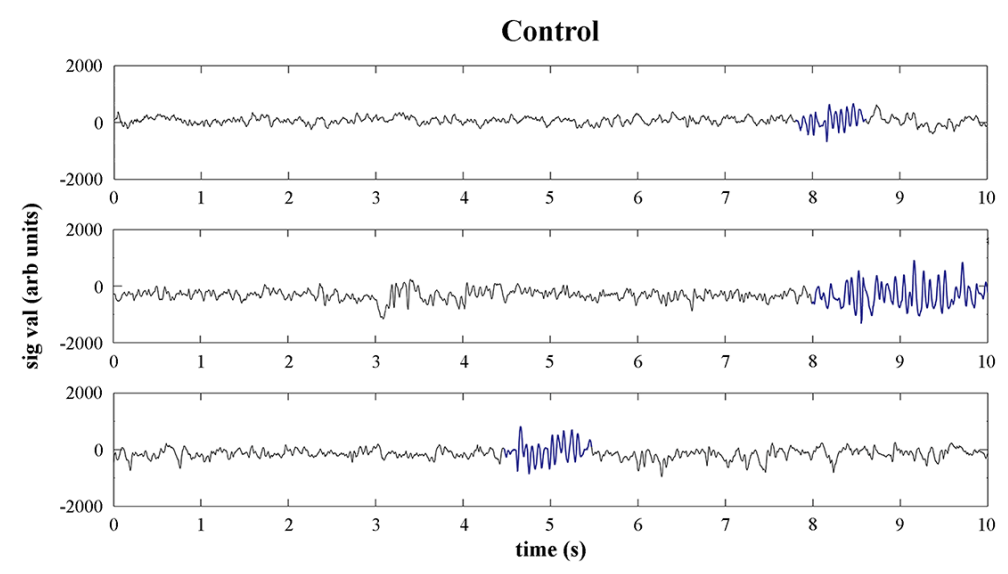

PPT lesion

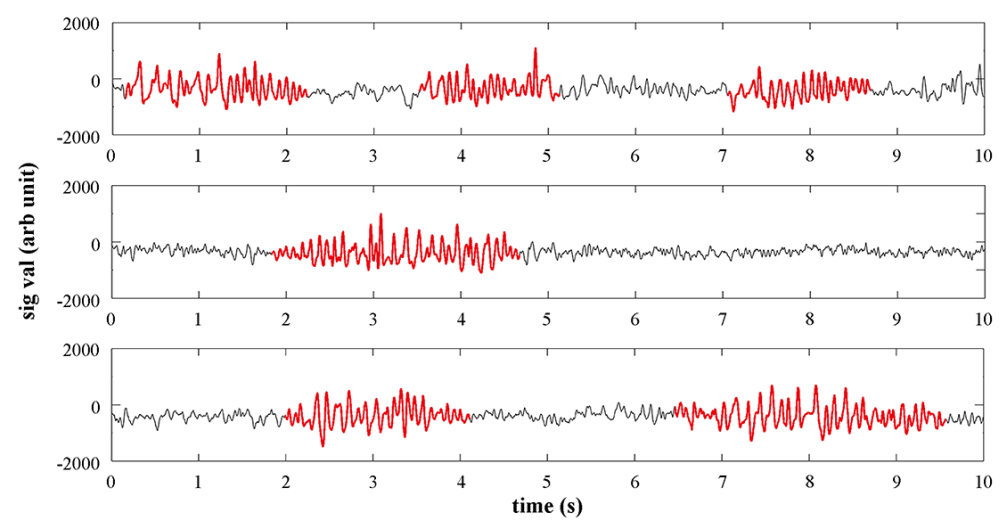

$\mathbf{B}$
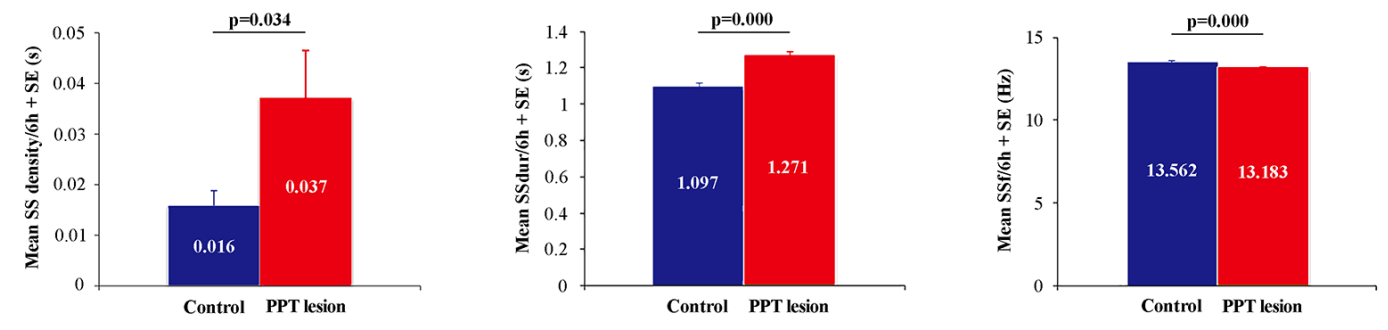

C
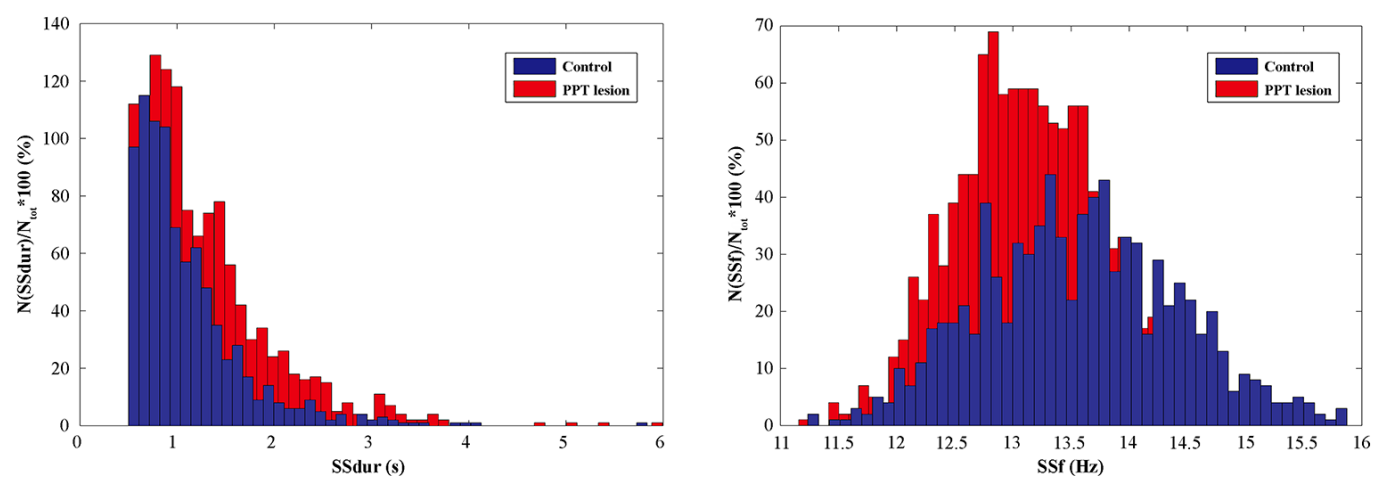

Figure 6. Sleep spindle (SS) dynamics during REM sleep in the motor cortex of PPT lesioned rats $(n=5)$ vs. controls $(n=7)$ at 4 and one half months of age (at the onset of REM sleep, the EEG was "enriched" (C) with sigma activity, see Fig. 5A). Individual examples of the analog $10 \mathrm{~s}$ epochs with visually detected sleep spindles of distinct pattern, duration, and intrinsic frequency (A) in a control (upper panels), and a PPT lesioned rat (bottom panels), with the group histograms of their mean SS density, duration, and intrinsic frequency per $6 \mathrm{~h}+\mathrm{SE}(\mathbf{B})$, and the group distributions of all SS durations (SSdur) and intrinsic frequencies (SSf) of the assembly of 842 SS extracted from 7 control rats vs. the assembly of 1216 SS extracted from 5 PPT lesioned rats. (C) $\mathrm{p}$ values correspond to the obtained significant result of Mann-Whitney U two-tailed test. 
loss of normal skeletal muscle atonia and dream enactment behavior during REM sleep $[37,38,39]$ very frequently go unnoticed in patients with neurodegenerative diseases, and as a symptom precedes the onset of motor and cognitive disturbances by years or even decades [34,40,41]. Although RBD can be triggered pharmacologically [42], it is generally related to structural lesions within the midbrain and pontomedullary brainstem, with the consequent disinhibited control of the motor cortex to the limbs, likely bypassing the basal ganglia or other modulatory structures $[34,38,42,43]$. In humans, RBD can be associated with pontomedullary strokes [34], narcolepsy, limbic encephalitis, Guillain-Barre syndrome, pharmacological agents (tricyclic or serotonergic antidepressants, alcohol or beta blockers), and with many neurodegenerative diseases including progressive supranuclear palsy, corticobasal syndrome, frontotemporal dementia, and Huntington's disease [42]. In addition, idiopathic RBD is most often caused by one of the synuclein-mediated neurodegenerative diseases (Parkinson's disease, Lewy body dementia, and multiple system atrophy), and more than $80 \%$ of patients with RBD eventually develop one of these diseases [44].

In addition, anatomical studies support the central role of the PPT in controlling REM sleep phenomena $[45,46]$, and show that direct projections from PPT reach both the basal forebrain and the thalamus [47], and therefore the PPT represents a higher control relay nucleus for the integrated contributions of the brain cholinergic system to the regulation of cortical activation[48,49]. Moreover, based on a number of the animal studies [50-52], the PPT has become the main target for deep brain stimulation for the treatment of movement and postural disorders in humans [53]. PPT as the main brain source of thalamocortical cholinergic innervation has an important functions relevant to the regulation of REM sleep [54,55], arousal [55,56], and various motor control systems [53,57], including breathing control [58-60]. In addition, in relation to motor and cognitive function control, particularly in relation to Parkinson's disease, the PPT is postulated as an important interface between the basal ganglia and cerebellum [61]. In addition, recent human studies demonstrated that cortical and thalamic subcortical cholinergic denervation due to the degeneration of PPT cholinergic neurons were related to RBD [62], as well as to gait and balance impairment, including falls in Parkinson's disease $[63,64]$.

Our previous studies demonstrated, in the rat model of severely impaired cholinergic thalamo-cortical innervation (our rat model of Parkinson's disease cholinergic neuropathology or Parkinson's disease cholinopathy), topographically differentially expressed EEG microstructure within the sensorimotor and motor cortex during NREM and REM sleep, along with the appearance of two REM sleep states, particularly within the motor cortex $[18,19]$. Moreover, these distinct REM states were differentiated with regard to: EEG microstructure, EMG power, and sensorimotor and motor cortical drive to the dorsal nuchal muscles [20]. These altered cortical drives were commonly expressed during both REM states as impaired beta oscillation drive, but the sensorimotor cortical drive was altered more severely during "normal" REM sleep (REM sleep with atonia, theta REM sleep) than during "pathological" REM sleep (REM sleep without atonia, sigma REM sleep). In addition, the hallmarks of an earlier aging onset during reduced thalamo-cortical cholinergic innervation were consistently expressed through increased EEG sigma amplitude in the motor cortex during REM sleep, as a unique REM sleep phenomenon, along with altered motor cortical drive (expressed as augmented delta, theta, sigma, and beta oscillations from the motor cortex that are related to the EMG activity of dorsal nuchal muscles) during NREM

\section{and REM sleep [16].}

Therefore, our recent studies suggest that certain sleep disorders, particularly REM sleep disorders, depict the potential functional biomarkers of neurodegeneration, that are relevant to Parkinson's disease and other synucleinopathies, and the biomarkers of an earlier aging onset in the brain with neurodegeneration versus physiologically healthy brain.

Results of our previous studies in animal models are in accordance with recent PET imaging studies in humans which demonstrated thalamic cholinergic denervation in Parkinson's disease with or without dementia in contrast to Alzheimer's disease, and suggested that the neurodegenerative involvement of thalamic cholinergic afferent projections may contribute to disease specific motor and cognitive abnormalities [62,64,65].

In addition, there is increasing evidence in human [66,67] and animal studies $[68,69]$ that abnormally synchronized oscillatory activity in the cortico-basal ganglia loop is associated with the motor deficits in Parkinson's disease, particularly beta synchronization (14$30 \mathrm{~Hz}$ ) and high voltage spindles $(5-13 \mathrm{~Hz})$. Our present results in the rat model of Parkinson's disease cholinopathy are in accordance with evidence that dopamine depletion in 6-OHDA lesioned rats increase the density and duration of the high voltage spindles, as a particular pattern of spindle activity that also reflects the state of thalamo-cortical regulatory network [68].

Sleep spindles are one of the basic thalamo-cortical EEG oscillations that classically contribute to sleep promotion and maintenance, and are associated to sensory gating, motor representation development, cognition, and memory consolidation [70]. Spindle frequency is basically determined by the interplay of GABAergic inhibitory neurons of the RT nucleus and the TC neurons, their intrinsic properties, and their influence by cortical descending and the brainstem ascending inputs. The duration of IPSPs imposed by RT neurons on TC neurons determines the intra-spindle frequency [70].

Since PPT cholinergic afferents inhibit RT neurons, the increased density of slower and longer sleep spindles within the motor cortex during REM sleep, in our present study, reflects changes within the thalamo-cortical regulatory network during REM sleep, caused by the attenuated inhibition of RT neurons by cholinergic afferents from the PPT, due to the PPT lesion. Moreover, these rearrangements within the thalamo-cortical regulatory network might be due to the tonically and sustainably decreased cholinergic inhibition of RT neurons and excitation of TC neurons across all sleep/wake states, particularly during REM sleep.

\section{Acknowledgement}

This work was supported by Serbian Ministry of Education, Science and Technological Development Grant OI 173022.

\section{References}

1. Penttonen M, Buzsaki G (2003) Natural logarithmic relationship between brain oscillators. Thalamus Relat Sys 2: 145-152.

2. Buzsáki G, Smith A, Berger S, Fisher LJ, Gage FH (1990) Petit mal epilepsy and parkinsonian tremor: hypothesis of a common pacemaker. Neuroscience 36: 1-14. [Crossref]

3. Ferrarelli F, Peterson MJ, Sarasso S, Riedner BA, Murphy MJ, et al. (2010) Thalamic dysfunction in schizophrenia suggested by whole- night deficits in slow and fast spindles. Am J Psychiatry 167: 1339-1348. [Crossref]

4. Christensen JA, Kempfner J, Zoetmulder M, Leonthin HL, Arvastson L, et al. (2014) 
Decreased sleep spindle density in patients with idiopathic REM sleep behavior disorder and patients with Parkinson's disease. Clin Neurophysiol 125: 512-519. [Crossref]

5. O'Relly C, Gosselin N, Carrier J, Nielsen T (2014) Montreal archive of sleep studies: an open-access resource for instrument benchmarking and exploratory research. $J$ Sleep Res 23: 628-635. [Crossref]

6. Montplaisir J, Petit D, Lorrain D, Gauthier S, Nielsen T (1995) Sleep in Alzheimer's disease: further considerations on the role of brainstem and forebrain cholinergic populations in sleep-wake mechanisms. Sleep 18: 145-148. [Crossref]

7. Rauchs G, Schabus M, Parapatics S, Bertran F, Clochon P, et al. (2008) Is there a link between sleep changes and memory in Alzheimer's disease? Neuroreport 19: 11591162. [Crossref]

8. Limoges E, Mottron L, Bolduc C, Berthiaume C, Godbout R (2005) Atypical sleep architecture and the autism phenotype. Brain 128: 1049-1061. [Crossref]

9. Shibagaki M, Kiyono S, Watanabe K (1982) Spindle evolution in normal and mentally retarded children: a review. Sleep 5: 47-57. [Crossref]

10. Fogel SM, Smith CT (2011) The function of the sleep spindle: a physiological index of intelligence and a mechanism for sleep-dependent memory consolidation. Neurosci Biobehav Rev 35: 1154-1165. [Crossref]

11. Schabus M, Dang-Vu TT, Heib DP, Boly M, Desseilles M, et al. (2012) The Fate of Incoming Stimuli during NREM Sleep is Determined by Spindles and the Phase of the Slow Oscillation. Front Neurol 3: 40. [Crossref]

12. Gottselig JM, Bassetti CL, Achermann P (2002) Power and coherence of sleep spindle frequency activity following hemispheric stroke. Brain 125: 373-383. [Crossref]

13. Iber C, Ancoli-Israel S, Chesson A, Quan SF (2007) AASM Manual for the Scoring of Sleep and Associated Events.

14. Sullivan D, Mizuseki K, Sorgi A, Buzsáki G (2014) Comparison of sleep spindles and theta oscillations in the hippocampus. J Neurosci 34: 662-674. [Crossref]

15. Warby SC, Wendt SL, Welinder P, Munk EGS, Carrillo O, et al. (2014) Sleep-spindle detection: crowdsourcing and evaluating performance of experts, non-experts and automated methods. Nat Methods 11: 385-392.

16. Ciric J, Lazic K, Petrovic J, Kalauzi A, Saponjic J (2016) Age-related disorders of sleep and motor control in the rat models of functionally distinct cholinergic neuropathology. Behav Brain Res 301: 273-286. [Crossref]

17. Saponjic J, Radulovacki M, Carley DW (2007) Monoaminergic system lesions increase post-sigh respiratory pattern disturbance during sleep in rats. Physiol Behav 90: 1-10. [Crossref]

18. Petrovic J, Ciric J, Lazic K, Kalauzi A, Saponjic J (2013a) Lesion of the pedunculopontine tegmental nucleus in rat augments cortical activation and disturbs sleep/wake state transitions structure. Exp Neurol 247: 562-571. [Crossref]

19. Petrovic J, Lazic K, Ciric J, Kalauzi A, Saponjic J (2013b) Topography of the sleep/ wake states related EEG microstructure and transitions structure differentiates the functionally distinct cholinergic innervation disorders in rat. Behav Brain Res 256: 108-118. [Crossref]

20. Petrovic J, Lazic K, Kalauzi A, Saponjic J (2014) REM sleep diversity following the pedunculopontine tegmental nucleus lesion in rat. Behav Brain Res 271: 258-268. [Crossref]

21. Ciric J, Lazic K, Petrovic J, Kalauzi A, Saponjic J (2015) Aging induced cortical drive alterations during sleep in rats. Mech Ageing Dev 146-148: 12-22. [Crossref]

22. Lazic K, Petrovic J, Ciric J, Kalauzi A, Saponjic J (2015) Impact of anesthetic regimen on the respiratory pattern, EEG microstructure and sleep in the rat model of cholinergic Parkinson's disease neuropathology. Neurosci 304: 1-13. [Crossref]

23. Lazic K, Petrovic J, Ciric J, Kalauzi A, Saponjic J (2017) REM sleep disorder following general anesthesia in rats. Physiol Behav 168: 41-54. [Crossref]

24. Saponjic J, Petrovic J, Ciric J, Lazic K (2016) Disorders of sleep and motor contro during the impaired cholinergic innervation in rat - relevance to Parkinson's disease. In: Challenges in Parkinson's Disease, J. Dorszewska and W. Kozubski, Eds. InTech Rijeka, Croatia, Ch 7, pp: 135-153.

25. Paxinos, G., Watson, C. The Rat Brain in Stereotaxic Coordinates. Fifth ed. 2005. Elsevier Academic Press, San Diego, US

26. Inglis WL, Semba K (1997) Discriminable excitotoxic effects of ibotenic acid, AMPA, NMDA and quinolinic acid in the rat laterodorsal tegmental nucleus. Brain Res 755: 17-27. [Crossref]
27. Adamczyk M, Genzel L, Dresler M, Steiger A, Friess E (2015) Automatic Sleep Spindle Detection and Genetic Influence Estimation Using Continuous Wavelet Transform. Front Hum Neurosci 9: 1-20. [Crossref]

28. Paxinos, G., Watson, C., Carrive, P., Kirkcaldie, M.,Ashwell, K.W.S. Chemoarchitectonic Atlas of The Rat Brain. Second ed. 2009. Academic Press, London, UK.

29. Biomarkers Definition Working Group (2011) Biomarkers and surrogate endpoints: preferred definitions and conceptual framework. Clin Pharmacol Ther 69: 89-95. [Crossref]

30. Dijk DJ (2016) Biomarkers, old and new: for sleep, sleepiness, circadian phase and much more. J Sleep Res 25: 255-256. [Crossref]

31. Grønli J, Rempe MJ, Clegern WC, Schmidt M, Wisor JP (2016) Beta EEG reflect sensory processing in active wakefulness and homeostatic sleep drive in quiet wakefulness. J Sleep Res 25: 257-268. [Crossref]

32. Schwabedal JT, Riedl M, Penzel T, Wessel N (2016) Alpha-wave frequency characteristics in health and insomnia during sleep. J Sleep Res 25: 278-286. [Crossref]

33. Iranzo A, Molinuevo JL, Santamaría J, Serradell M, Martí MJ, et al. (2006) Rapid-eyemovement sleep behaviour disorder as an early marker for neurodegenerative disorder: a descriptive study. Lancet Neurol 5: 572-577. [Crossref]

34. Boeve BF, Silber MH, Saper CB, Ferman TJ, Dickson DW, et al. (2007)Pathophysiology of REM sleep behaviour disorder and relevance to neurodegenerative disease. Brain 130: 2770-2788. [Crossref]

35. Iranzo A, Tolosa E, Gelpi E, Molinuevo JL, Valldeoriola F, et al. (2013) Neurodegenerative disease status and post-mortem pathology in idiopathic rapid-eyemovement sleep behaviour disorder: an observational cohort study. Lancet Neurol 12 : 443-453. [Crossref]

36. Peever J, Luppi PH, Montplaisir J (2014) Breakdown in REM sleep circuitry underlies REM sleep behavior disorder. Trends Neurosci 37: 279-288. [Crossref]

37. Ju YE, Larson-Prior L, Duntley S (2011) Changing demographics in REM sleep behavior disorder: possible effect of autoimmunity and antidepressants. Sleep Med 12 : 278-283. [Crossref]

38. Luppi PH, Clément O, Sapin E, Gervasoni D, Peyron C, et al. (2011) The neuronal network responsible for paradoxical sleep and its dysfunctions causing narcolepsy and rapid eye movement (REM) behavior disorder. Sleep Med Rev 15: 153-163. [Crossref]

39. Schenck CH, Bundlie SR, Ettinger MG, Mahowald MW (1986) Chronic behaviora disorders of human REM sleep: a new category of parasomnia. Sleep 9: 293-308. [Crossref]

40. Whitwell JL, Weigand SD, Shiung MM, Boeve BF, Ferman TJ, et al. (2007) Foca atrophy in dementia with Lewy bodies on MRI: a distinct pattern from Alzheimer's disease. Brain 130: 708-719. [Crossref]

41. Simic G, Stanic G, Mladinov M, Jovanov-Milosevic N, Kostovic I, et al. (2009) Does Alzheimer's disease begin in the brainstem? Neuropathol Appl Neurobiol 35: 532-554. [Crossref]

42. Postuma RB, Gagnon JF, Montplaisir JY (2012) REM sleep behavior disorder: from dreams to neurodegeneration. Neurobiol Dis 46: 553-558. [Crossref]

43. Sapin E, Lapray D, Bérod A, Goutagny R, Léger L, et al. (2009) Localization of the brainstem GABAergic neurons controlling paradoxical (REM) sleep. PLoS One 4 e4272. [Crossref]

44. Boeve BF (2013) Idiopathic REM sleep behaviour disorder in the development of Parkinson's disease. Lancet Neurol 12: 469-482. [Crossref]

45. Semba K (1993) Aminergic and cholinergic afferents to REM sleep induction regions of the pontine reticular formation in the rat. J Comp Neurol 330: 543-556. [Crossref]

46. Rye DB (1997) Contributions of the pedunculopontine region to normal and altered REM sleep. Sleep 20: 757-788. [Crossref]

47. Losier BJ, Semba K (1993) Dual projections of single cholinergic and aminergic brainstem neurons to the thalamus and basal forebrain in the rat. Brain Res 604: 41-52. [Crossref]

48. Sarter M, Bruno JP (2000) Cortical cholinergic inputs mediating arousal, attentiona processing and dreaming: differential afferent regulation of the basal forebrain by telencephalic and brainstem afferents. Neurosci 95: 933-952. [Crossref]

49. Dringenberg HC, Olmstead MC (2003) Integrated contributions of basal forebrain and thalamus to neocortical activation elicited by pedunculopontine tegmental stimulation in urethane-anesthetized rats. Neurosci 119: 839-853. [Crossref] 
50. Garcia-Rill E (1986) The basal ganglia and the locomotor regions. Brain Res 396: $47-$ 63. [Crossref]

51. Garcia-Rill E (1991) The pedunculopontine nucleus. Prog Neurobiol 36: 363-389. [Crossref]

52. Garcia-Rill E (1997) Disorders of the reticular activating system. Med Hypotheses 49: 379-387. [Crossref]

53. Garcia-Rill E, Hyde J, Kezunovic N, Urbano FJ, Petersen E (2015) The physiology of the pedunculopontine nucleus: implications for deep brain stimulation. $J$ Neural Transm (Vienna) 122: 225-235. [Crossref]

54. Lu J, Sherman D, Devor M, Saper CB (2006) A putative flip-flop switch for control of REM sleep. Nature 441: 589-594. [Crossref]

55. Urbano FJ, D’Onofrio SM, Luster BR, Beck PB, Hyde JR, et al. (2014) Pedunculopontine nucleus gamma band activity-preconscious awareness, waking, and REM sleep. Front Neurol 5: 1-12.

56. Datta S, Maclean RR (2007) Neurobiological mechanisms for the regulation of mammalian sleep-wake behavior: reinterpretation of historical evidence and inclusion of contemporary cellular and molecular evidence. Neurosci Biobehav Rev 31: 775-824. [Crossref]

57. Takakusaki K, Habaguchi T, Saitoh K, Kohyama J (2004) Changes in the excitability of hindlimb motoneurons during muscular atonia induced by stimulating the pedunculopontine tegmental nucleus in cats. Neurosci 124: 467-480. [Crossref]

58. Saponjic J, Radulovacki M, Carley DW (2003) Respiratory pattern modulation by the pedunculopontine tegmental nucleus. Respir Physiol Neurobiol 138: 223-237. [Crossref]

59. Saponjic J, Cvorovic J, Radulovacki M, Carley DW (2005) Serotonin and noradrenaline modulate respiratory pattern disturbances evoked by glutamate injection into the pedunculopontine tegmentum of anesthetized rats. Sleep 28: 560-570. [Crossref]

60. Saponjic J, Radulovacki M, Carley DW (2006) Modulation of respiratory pattern and upper airway muscle activity by the pedunculopontine tegmentum: role of NMDA receptors. Sleep Breath 10: 195-202. [Crossref]

61. Mori F, Okada KI, Nomura T, Kobayashi Y (2016) The pedunculopontine tegmental nucleus as a motor and cognitive interface between the cerebellum and basal ganglia. Front Neuroanat 10: 1-8. [Crossref]

62. Kotagal V, Albin RL, Müller ML, Koeppe RA, Chervin RD, et al. (2012) Symptoms of rapid eye movement sleep behavior disorder are associated with cholinergic denervation in Parkinson disease. Ann Neurol 71: 560-568. [Crossref]

63. Bohnen NI, Müller ML, Koeppe RA, Studenski SA, Kilbourn MA, et al. (2009) History of falls in Parkinson disease is associated with reduced cholinergic activity. Neurology 73: 1670-1676. [Crossref]

64. Bohnen NI, Albin RL (2011) The cholinergic system and Parkinson disease. Behav Brain Res 221: 564-573. [Crossref]

65. Kotagal V, Müller ML, Kaufer DI, Koeppe RA, Bohnen NI (2012b) Thalamic cholinergic innervation is spared in Alzheimer disease compared to parkinsonian disorders. Neurosci Lett 514: 169-172. [Crossref]

66. Garcia L, D'Alessandro G, Bioulac B, Hammond C (2005) High-frequency stimulation in Parkinson's disease: more or less? Trends Neurosci 28: 209-216. [Crossref]

67. Quiroga-Varela A, Walters JR, Brazhnik E, Marin C, Obeso JA (2013) What basa ganglia changes underlie the parkinsonian state. The significance of neuronal oscillatory activity. Neurobiol Dis 58: 242-248.

68. Ge S, Yang C, Li M, Li J, Chang X, et al. (2012) Dopamine depletion increase the power and coherence of high-voltage spindles in the globus pallidus and motor cortex of freely moving rats. Brain Res 1465: 66-79. [Crossref]

69. Yang C, Zhang JR, Chen L, Ge SN, Wang JL, et al. (2015) High frequency stimulation of the STN restored the abnormal high-voltage spindles in the cortex and the globus pallidus of 6-OHDA lesioned rats. Neurosci Lett 595: 122-127. [Crossref]

70. Urakami Y, Ioannides AA, Kostopoulos GK (2012) Sleep Spindles - As a Biomarker of Brain Function and Plasticity. In: Advances in Clinical Neurophysiology, I. M. Ajeena, Eds. 2012. InTech, Rijeka, Croatia, pp. 73-153.

Copyright: (C2017 Ciric J. This is an open-access article distributed under the terms of the Creative Commons Attribution License, which permits unrestricted use, distribution, and reproduction in any medium, provided the original author and source are credited. 